\title{
Stimulation of decidua development by transplantation of endometrial stem cells
}

\author{
Alisa P. Domnina, Victoria I. Zemelko, Vyacheslav M. Mikhailov, Nikolay N. Nikolsky \\ Institute of Cytology, Russian Academy of Sciences, St.-Petersburg, Russia \\ Email: aldomnina@mail.ru, vzemelko@mail.ru
}

Received 13 June 2013; revised 15 July 2013; accepted 29 July 2013

Copyright (C) 2013 Alisa P. Domnina et al. This is an open access article distributed under the Creative Commons Attribution License, which permits unrestricted use, distribution, and reproduction in any medium, provided the original work is properly cited.

\begin{abstract}
On all terms of pregnancy, insolvency of decidual reaction of endometrial cells is one of the reasons of miscarriages and fetal growth delay. The insufficient decidualization of endometrum leads to infertility in such pathologies, as Asherman's syndrome and an endometrium atrophy. However, there are data on successful application of autologous bone marrow MSCs for Asherman's syndrome treatment. The aim of this work was to assay the effect of endometrial mesenchymal stem cell (eMSC) transplantation for decidualization process in pseudopregnant rat. Our study showed that injection of human eMSC suspension into the uterine lumen of pseudopregnant rats facilitated more intensive development of decidua in comparison with phosphate buffed saline (PBS) injection in the control uterine horn. Histological analysis of decidua sections did not reveal any alterations in cell differentiation or tissue structure. In conclusion, we demonstrated for the first time that eMSC transplantation assists the development of all decidual tissue elements. It opens the possibility that eMSCs may be applied for cell therapy of infertility associated with decidualzation insufficiency.
\end{abstract}

Keywords: Decidualization; Pseudopregnancy; Human Mesenchymal Stem Cells of Endometrium; Menstrual Blood

\section{INTRODUCTION}

During pregnancy, specific morphological and biochemical change named decidual reaction occurs in stromal cells of the uterus. Decidualization of endometrium is an essential process for embryo implantation, placenta forming and maintenance of pregnancy [1]. Several biological functions have been attributed to decidual cells: a nutritive role for the embryo, secretion of prolactin [2],
IGFBP-1 [3], and prostaglandins and maintenance of pregnancy by protecting maternal tissue from destructive invasion of trophoblast cells of the placenta and allogeneic fetoplacental unit from an immunological rejection by the mother [4]. For decidualization to occur, uterus should to be prepared by estrogens and progesterone and then for a stimulus, normally provided by the blastocyst attached to the endometrium [5-7]. The nature of the stimulus for decidualization is still unknown. On pseudopregnant rodents, it was shown that the uterus could be stimulated to produce decidual cells in the absence of a blastocyst by traumatization of endometrium. Data show that different substances injected directly into the uterine lumen of pseudopregnant animals can induce decidualization [8]. Pseudopregnancy is a condition characterized by many features of early pregnancy: presence of large functional corpora lutea, development of the mammary glands, and progestational changes in the uterine mucosa with susceptibility to decidua formation. Pseudopregnancy can be induced by electrical stimulation of the cervix uteri during oestrus or using vasectomied males [9]. Artificial decidua is analogous to the decidual reaction of normal implantation: it is histologically similar, and the hormonal requirements for its formation are similar to those for implantation [10]. Decidual tissue is formed by large decidual cells (LDC), endometrial granulated cells (eGC) and small decidual cells. The LDC form the main type of decidual membranes, which determine the morphological characteristics of the decidua as a tissue. Immediate precursor cells of LDC are located below the basement membrane of the uterine epithelium before and during implantation [11]. It is assumed that a partial source of stromal cells in endometrial tissue is bone marrow cells $[12,13]$. To date, mesenchymal stem cells (MSC) have been established from endometrium and menstrual blood $[14,15]$. The isolated endometrial MSC (eMSC) is a heterogeneous population composed mainly of stromal cells. Endometrial MSCs (eMSCs) express the same 
markers as bone marrow MSCs do. The eMSCs from endometrium are able to differentiate into nine cell types out of the three germ layers: mesoderm (bone, cartilage, muscle, tendon and ligament cells), ectoderm (neurons, astrocytes), and endoderm (liver, intestine, ling and pancreatic cells) [16-18].

We established cell lines of multipotent human mesenchymal stem cell from desquamated (shedding) endometrium of menstrual blood (eMSCs). The eMSCs have positive expression of CD13, CD29, CD44, CD73, CD90, and CD105 markers and lack hematopoietic cell surface antigens CD19, CD34, CD45, CD117, CD130, and HLADR (class II). Multipotency of the established eMSCs is confirmed by their ability to differentiate into other mesodermal lineages, such as osteocytes and adipocytes. The established eMSC cell lines meet the criteria of the International Society for Cellular Therapy for defining multipotent human MSCs of any origin [19].

The aim of this work was to study the effect of the human eMSCs to decidual differentiation of endometrium. To this end, a model of pceudopregnancy in rat was used.

\section{MATERIALS AND METHODS}

\section{1. eMSCs Derivation and Cultivation}

eMSCs lines were isolated as has been previously described [19]. Briefly, menstrual blood with endometrium fragments was obtained from women with age varied from 30 to 40 years. All women gave written informed consent for the procedure. Blood was collected on the second day of the menstrual blood flow. The blood was centrifuged; a pellet with endometrium fragments was resuspended in PBS with $10 \%$ antibiotic-antimycotic mixture, incubated for $1 \mathrm{~h}$ at $37^{\circ} \mathrm{C}$ and centrifuged. The cell pellet was seeded in $6 \mathrm{~cm}$ Petri dishes (Corning, United States) in DMEM/F12 medium with $10 \%$ fetal calf serum (FCS) (HyClone, United States), 1\% antibiotic-antimycotic mixture, $1 \%$ glutamax. The cells were cultivated for 3 - 7 days. The medium was exchanged several times during this period; therefore, only adhesive cells composed the culture.

\subsection{Flow Cytometry}

The eMSCs immunophenotyping (CD marker expression) was performed with an Epics XL flow cytometer (Beckman Coulter, United States). The single cell suspension was obtained using $0.05 \%$ trypsin/EDTA. $1 \times 10^{6}$ cells were suspended in $1 \mathrm{~mL}$ of PBS with $5 \%$ FCS. FITC conjugated antibodies to CD34, CD44, CD45, CD90, CD130, and PE (phycoerythrin) antibodies to CD13, CD19, CD29, CD73, CD105, CD117 and HLA DR were applied.

\subsection{Immunocytochemistry}

To visualize surface antigen SSEA-4, live eMSCs were incubated with mouse monoclonal antibodies to SSEA 4 (Chemicon, United States) (1:50). Immunofluorescent staining for Oct- 4 , nestin, and $\beta$-III-tubulin was done according to the routine protocol. The antibodies used were mouse monoclonal to Oct4 (1:50) (Santa Cruz, United States), mouse monoclonal to $\beta$ III tubulin (1:1000) (Chemicon, United States), rabbit polyclonal to nestin $(1: 100)$ (Chemicon, United States), and rabbit polyclonal to $\beta$ III tubulin (1:100) (Sigma, United States). The secondary antibodies were goat anti rabbit antibodies conjugated with CY2 (1:300) and goat antibodies to antimouse immunoglobulins labeled with CY3 (1:300) (Chemicon, United States) or Dylight 488 (1:400) (Jackson Immuno-research, United States).

\subsection{Adipogenic Differentiation}

$2 \times 10^{4}$ cells $/ \mathrm{cm}^{2}$ was seeded in Petri dishes coated with $0.1 \%$ gelatin (Sigma, United States). When the cells reached about $80 \%$ confluence, $1 \mathrm{mM}$ dexamethasone (Sigma, United States), $0.5 \mathrm{mM}$ isobutylmethylxanthine (IBMX; Sigma, United States), $10 \mu \mathrm{g} / \mathrm{mL}$ human recombinant insulin (Sigma, United States) and $100 \mathrm{mM}$ indometacin were added. The cells were cultivated in the differentiation medium for 5 days with a half volume of the medium changed every other day. Under these conditions the cells have been differentiated for 3 - 5 weeks. Lipid drops were visualized with Oil Red staining (Sigma, United States) according to the manufacturer's instructions.

\subsection{Osteogenic Differentiation}

$2 \times 10^{4}$ cells $/ \mathrm{cm}^{2}$ was seeded in Petri dishes coated with $0.1 \%$ gelatin, The cells reached $100 \%$ confluence 100 $\mathrm{nM}$ dexamethasone, $10 \mathrm{mM} \beta$ glycerol phosphate and 0.2 $\mathrm{mM}$ ascorbate 2 phosphate were added. In this medium, the cells were differentiated for 3 - 5 weeks with a half volume of the medium changed every 2 - 3 days. Then, the cells were fixed with $70 \%$ cold ethanol for $1 \mathrm{~h}$ and stained with Alizarin Red, pH 4.1 (Sigma, United States).

\subsection{Bone Marrow Isolation}

Bone marrow was flushed from the femurs and tibias of rats and washed with phosphate buffed solution without $\mathrm{Ca}^{2+}$ and $\mathrm{Mg}^{2+}$ (Sigma-Adrich, United States). The bone marrow cell suspension was fractionated in $63 \%$ Percoll (Sigma-Adrich, United States) and centrifuge on $1500 \mathrm{~g}$ for $15 \mathrm{~min}$, and then washed with phosphate buffed solution without $\mathrm{Ca}^{2+}$ and $\mathrm{Mg}^{2+}$. Total bone marrow cells (rBMC) were counted using Gorjaev's chamber. 


\subsection{Cell Tracking}

For cell tracking in vivo vital dyes were used. Double staining with membrane dye PKH 67 Green (SigmaAdrich, United States) and nuclear staining dye Hoechst 332 (Sigma-Adrich, United States) were applied for transplanted cells according to the manufacturer's instructions. Staining efficiency was assayed by fluorescent microscopy of cells in culture.

\subsection{Animal Model}

Adult albino rat females weight 200 - 250 g were maintained in the designated animal care facility according to the institutional guidelines for the care and use of laboratory animals. Vaginal cytology was performed to assess for estrous cyclicity. A sterile swab was moistened with saline and rotated against the vaginal wall to obtain vaginal cells. Vaginal smears were visualized with the light microscope. Animals were divided into 2 groups. In first group $5 \times 10^{5}$ eMSC single cell suspension in $20 \mu \mathrm{l}$ PBS and of $20 \mu \mathrm{l} \mathrm{PBS}$ without cells were injected into the experimental uterine horn and contralateral control horn, respectively. In second group $20 \times 10^{6}$ rBMC single cell suspension in $20 \mu \mathrm{l}$ PBS and of $20 \mu \mathrm{l}$ PBS without cells were injected into the experimental uterine horn and contralateral control horn, respectively. The artificial decidual response has been induced by electrical stimulation of the cervix during oestrus. On the 5-th day of pseudopregnancy animals were anesthetized by intramuscular injection of Zoletil 100 (Virbac, France) in dose $5 \mathrm{mg} / \mathrm{kg}$ weight; surgical manipulations were done under aseptic conditions. The animals were fixed in a dorsal position and double sections of skin and muscles $1.5 \mathrm{~cm}$ laterally the vertebrae were done. Uterus horns were pulled out very carefully to avoid any traumatization and single cell suspension of eMSC or $\mathrm{rBMC}$ were injected into one of the uterine horns. $20 \mu \mathrm{l}$ of PBS without cells were introduced into the contralateral horn served as control. Rats were sacrificed on 11 day of pseudopregnancy. To estimate the deciduas development in experimental and control uterine horns uteri were collected and weighed.

\subsection{Histology}

Frozen $15 \mu \mathrm{m}$ sections of formed artificial deciduas were done parallel to a mesometral-antiesometral axis of horns of a uterus. Slides were fixed in ethanol/methanol mixture for $2 \mathrm{~min}$ at $-20^{\circ} \mathrm{C}$ and were stained with hematoxylin and eosin. Differentiation level of decidua in the mezometralnom-antimezometralny direction and structural alteration in decidual tissue, presence of inflammation and necrosis areas were assessed by light microscopy.

\section{RESULTS AND DISCUSSION}

Human endometrium composed of endometrial glands outlined with stroma is a dynamic tissue undergoing about 400 cycles of regeneration, differentiation, and shedding [20]. It was found that endometrium fragments in the menstrual blood are the source of stem cells. We established cell lines of mesenchymal stem from desquamated endometrium in menstrual blood (eMSC). Figure 1(a) illustrates the eMSC in culture. These cells have a fibroblast-like shape and generate a monolayer with a typical rounded swirling (Figure 2(a)). Human endometrium composed of glands is surrounded by stroma. Cloning of early passage cells showed that the isolated plastic adhesive eMSC is a population composed of stromal cells. Flow cytometry assay showed that the eMSCs expressed CD13, CD29, CD44, CD73, CD90, and CD105 and did not express hematopoietic markers CD19, CD34, CD45, CD117, CD130, and HLA-DR (class II) (Figure 3). This expression pattern satisfies the requirements suggested by the International Society for Cellular Therapy for the human MSC phenotyping based on surface markers. It was found that more than $50 \%$ of the eMSCs express SSEA-4, a pluripotent marker of human embryonic stem cells. In human embryonic stem cells, the SSEA-4 anti-

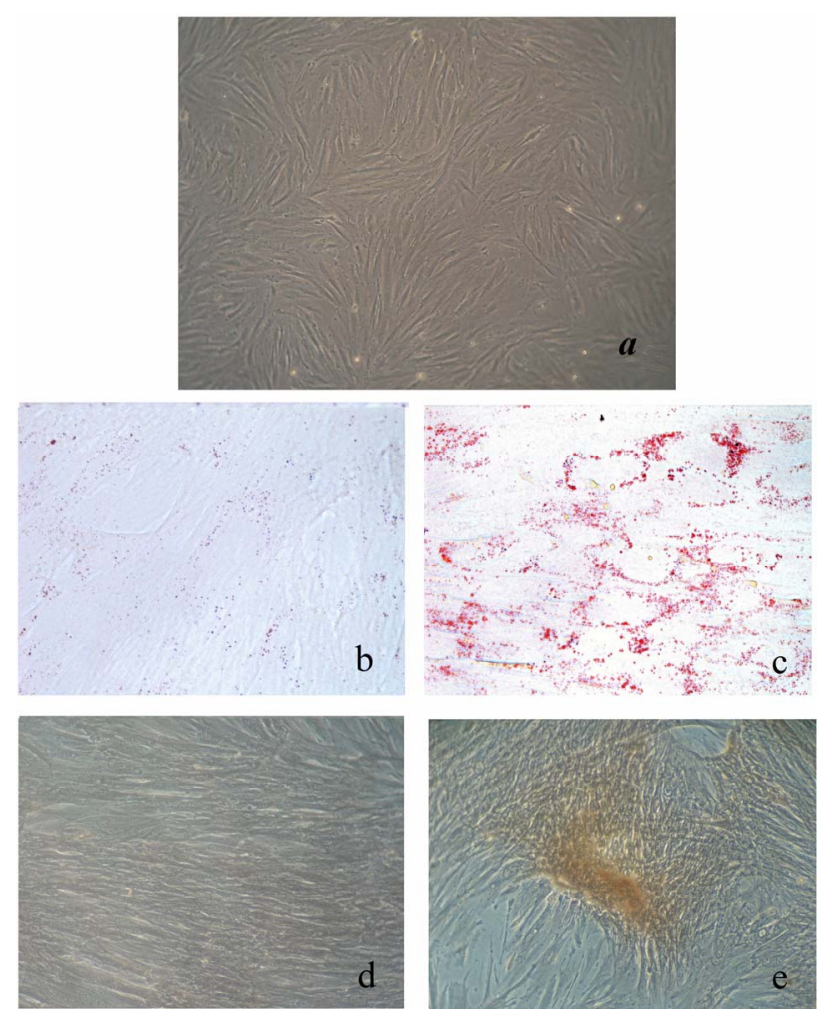

Figure 1. (a) Morphology of the established endometrial mesenchymal stem cells (eMSCs). Induced differentiation of the obtained eMSCs into mesoderm lineages: (b, c) adipocytes, (b) control undifferentiated cells stained by oil red; (b) differentiated cells with lipid vacuoles stained by oil red; (d, e) osteoblasts, (d) control undifferentiated cells stained with alizarin red, (e) calcium deposits of differentiated cells stained with alizarin red. Ob. $10 \times$ (a); Ob. $40 \times$ (b), (c); Ob. $20 \times$ (d), (e). 

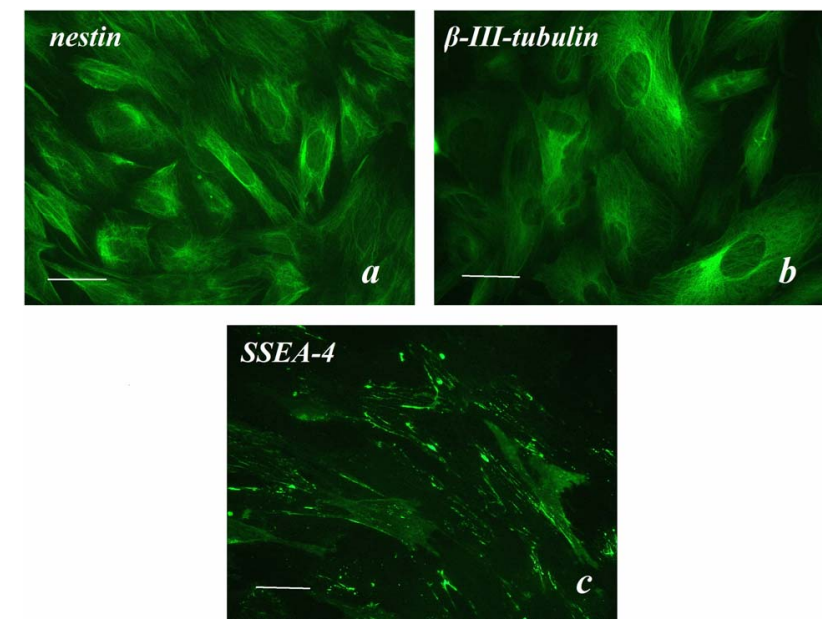

Figure 2. Expression of the phenotypic markers in the eMSCs. (a) nestin, (b) $\beta$-III-tubulin and (c) SEEA-4, Scale bar is 25 (a), (d) and 10 (c) $\mu \mathrm{m}$.

gen is localized on the cell surface uniformly, whereas in the eMSCs it is concentrated in focal adhesions (Figure 2(c)). However, expression of Oct-4, another pluripotent marker, was not detected in the eMSCs by either immunofluorescence or polymerase chain reaction. The eMSCs are positive for nestin (Figure 2(a)), a marker of early neuronal precursors, and $\beta$-III-tubulin (Figure 2(b)), a marker of late neuronal precursors. Nestin and $\beta$-III-tubulin expression in the cytoskeleton of the eMSCs from menstrual blood signifies that they are probably, predisposed to differentiate into neurons and astrocytes [21]. The International Society for Cellular Therapy defines multipotency of any human MSCs as a cell capacity to differentiate under certain stimuli into other mesoderm lineages. Figure 1 illustrates the differentiation of eMSCs into adipocytes (Figures 1(b) and (c)) and osteoblasts (Figures 1(d) and (e)). Both differentiated cultures have specific histological features. Adipocytes are characterized by accumulation of lipid droplets; osteoblasts have calcium deposits. Lipid drops stained with oil red are located in the perinuclear area of the differentiated adipocytes (Figure 1(c)). Figure 1(e) shows calcium deposits stained with alizarin red in the osteoblasts differentiated from the eMSCs. The frequency of adipogenic and osteogenic differentiation in our experiments was $70-80$ and $30 \%$, respectively.

Thus, eMSC is established from the menstrual blood meeting all the criteria of human multipotent MSC. eMSC derived from menstrual blood have been successfully used as a feeder layer for cultivation of human embryonic stem cells that mimic the earliest stage of the human embryonic development [19].

In this work we assayed the effect of human eMSCs on decidualization processes using pseudopregnancy in rats as a model. At the 11th day of pseudopregnancy more intensive development of decidua was observed in the experimental horn after inoculation of human eMSC suspension into the uterine lumen than in control uterine horn after PBS injection. To exclude that effect due to the fact that transplanted human eMSC are xenogenic, we used rat BMC (rBMC) in the same model. Figure 4(d) illustrates a significant difference in size of experimental and control horns after eMSC transplantation. The same result was obtained with $\mathrm{rBMC}$. Visible difference in the size of experimental and control horns was quantitated by weighing of isolated decidual tissue (Figure 3). It is seen (Figure 5) that the weight of decidual tissue in experimental horns three times exceeds the weight of this tissue in control in both groups of animals. It implies that both eMSC and rBMC translation stimulate decidualization in animals. Histological analysis of decidua sections did not reveal any alterations in cell differentiation or tissue structure after human eMCS or rBMC transplantation in a uterus of pseudopregnant rats (Figures 4(a)-(c)).

It is known that mesometrial part of rodent decidua is formed by large decidual cells (LDC) [11]. Huge polygonal LDC of antimesometrial part of decidua are seen in Figure 4(c). Figure 4(b) demonstrates mesometrial part of the decidua is composed of small decidual cells. The ratio of antimezometrial part of rat decidua constitutes from $30 \%$ to $40 \%$ of the area of a whole decidua section. Mezometrial part of decidua consists of small decidual cells and endometrial granulated cells (Figure 4(b)). Decidua on perpendicular section has an oval shape and its diameter size allows to compare different decidua by their area. For an assessment of transplantation effect of stem cells on LDC differentiation as the most differentiated decidual compartment, size of LDC zone relative to the whole dicidua area was measured. The morphometric results are presented in Table 1. The decidua from experimental uterine horns 1.5 - 2 times increased in diameter in the meso-antimezometralnom direction compared to the diameter of decidua in control horns. Table 1 illustrates the fact that LDC zone ratio in decidua section remained stable in all deciduas. Thus, transplantation does not cause alterations in the tissue structure; the increase in the decidua size results in intensived development of all elements of decidual tissue. Transplanted human eMSC and rBMC were found in decidual tissue in 6 days after transplantation. Figure 6(a) shows blue fluorescence of nuclei and green fluorescence of membranes in cultured eMSC double stained with membrane dye PKH 67 Green (Sigma-Adrich, United States) and nuclear staining dye Hoechst 332 (Sigma-Adrich, United States). Blue and green signals are also seen on tissue sections of deciduas from animals with transplanted eMSC (Figure 6(b)). No leukocyte infiltration in sites of transplanted cells was found. (Figures 4(a)-(c). Immunosuppres- 
FITC
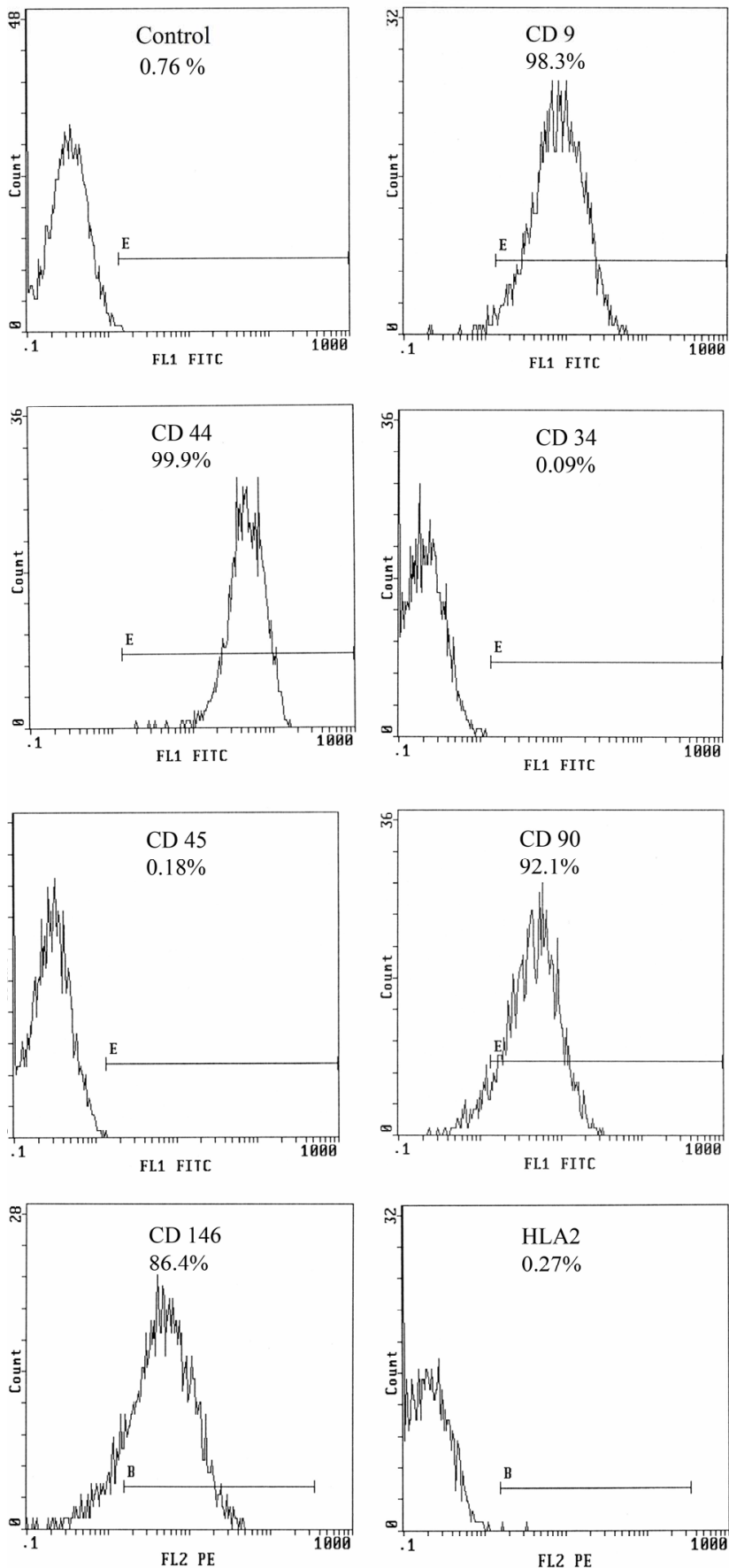
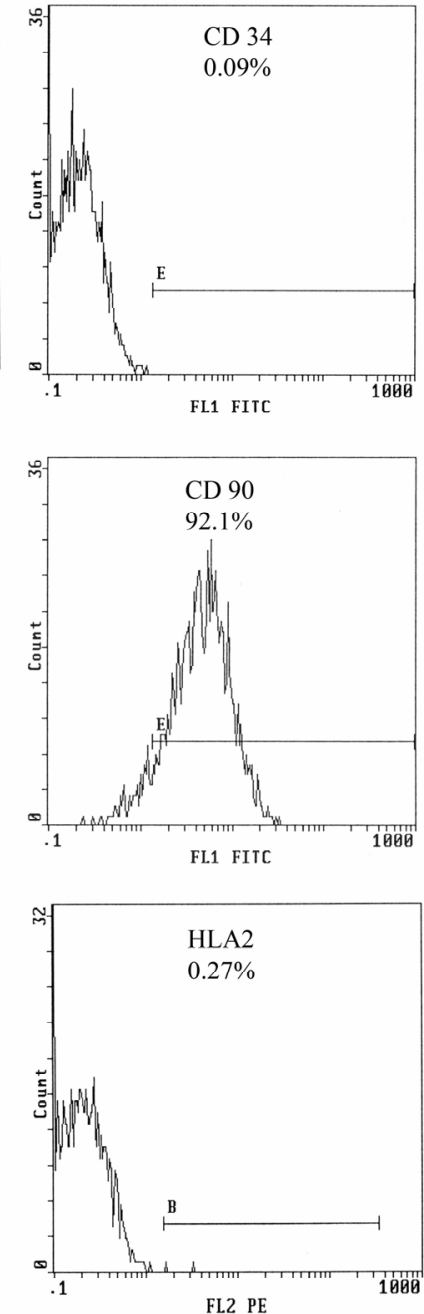

PE
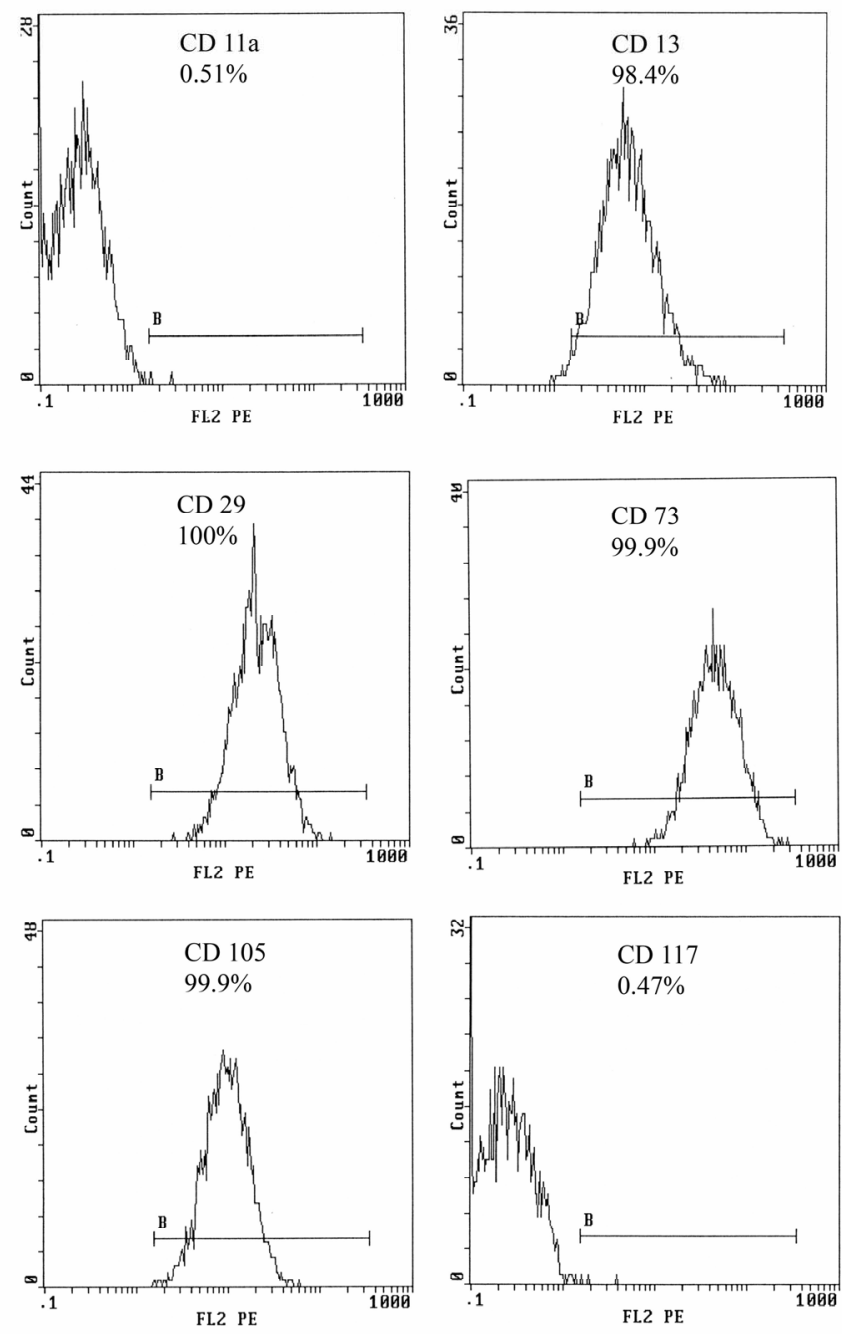

Figure 3. Expression of the surface markers in the derived eMSCs. Flow cytometry. Abscissa-fluorescence intensity; ordinate-cell number; FITC_FITC-stained cells; PE—phycoerythrin-stained cells.

sive ability of the decidual tissue has been reported in many studies. For example, primary allogeneic skin grafts transplanted into the decidualized uterus of pseudopregnant rats survived significantly longer than those inserted into nondecidualized uteri [22]. On all terms of pregnancy, insolvency of decidual reaction of endometrial cells is one of the reasons of miscarriages and fetal growth delay
[23]. The insufficient decidualization of endometrum leads to infertility in such pathologies, as Asherman's syndrome and an endometrium atrophy. The frequency of Asherman's syndrome occurrence in the women underwent hysteroscopy is $1.55 \%$ and $39 \%$ in women with recurrent miscarriage [24]. Currently, this disease is treated by surgery with subsequent cyclic hormonal therapies 


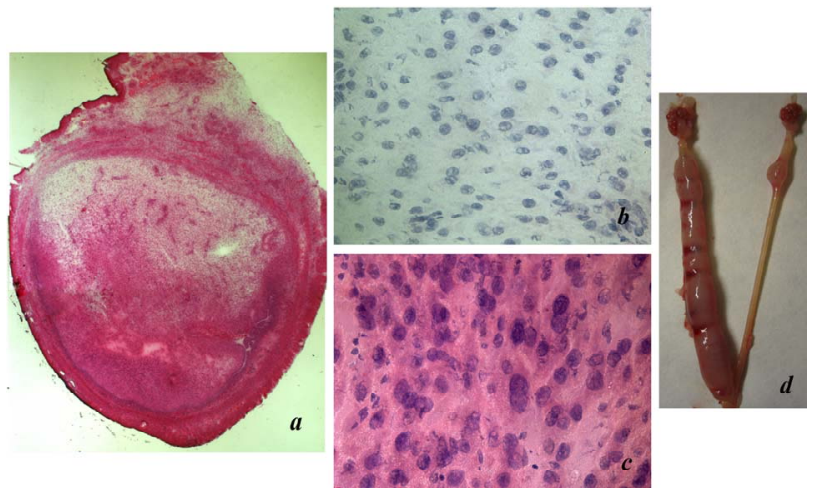

Figure 4. (a) Histological section of pseudopregnant rat's uterus after human endometrial mesenchymal stem cells (eMSC) transplantation. Hematoxylin and eosin staining. Ob. 5×; (b) Mesometrial part of decidua after eMSC injection. Hematoxylin and eosin staining Ob. 20×; (c) Antimesometrial part of decidua after eMSC injection. Hematoxylin and eosin staining Ob. 20×; (d) Rat's uterus on 11th day of pseudopregnancy after inoculation of human eMSC suspension into the uterine lumen: experimental horn (left) and control uterine horn after PBS injection (right).

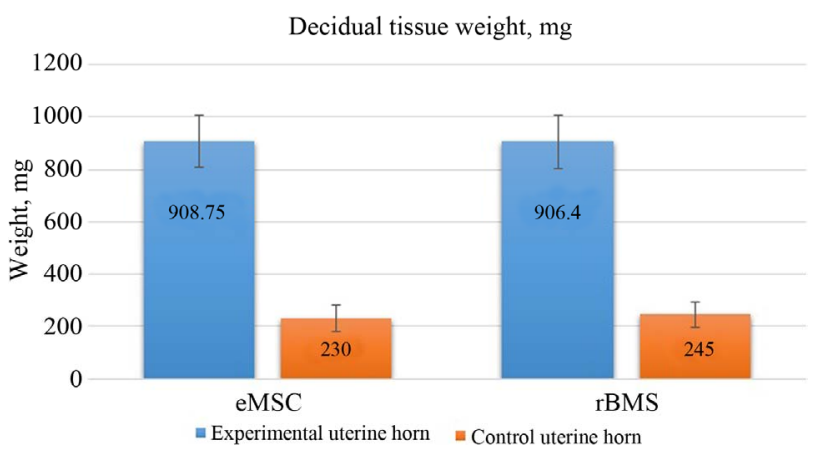

Figure 5. Decidual tissue weight of experimental and control uterine horns after injections of human endometrial mesenchymal stem cells (eMSC) and rat bone marrow cells (rBMC).

Table 1. Results of rat deciduas sections morphometric after transplantations of endometrial mesenchymal stem cells (eMSC) and rat bone marrow cells (rBMC).

\begin{tabular}{lcc}
\hline \multicolumn{1}{c}{$\begin{array}{c}\text { Rat deciduas on 11th day } \\
\text { of pseudopregnancy }\end{array}$} & $\begin{array}{c}\text { Experimental } \\
\text { decidua }\end{array}$ & Control decidua \\
\hline $\begin{array}{l}\text { Decidua diameter size after eMSC } \\
\text { transplantation (mm) }\end{array}$ & $4.3 \pm 0.5$ & $2.6 \pm 0.5$ \\
$\begin{array}{l}\text { Decidua diameter size after rBMC } \\
\text { transplantation (mm) }\end{array}$ & $4.6 \pm 0.3$ & $3.1 \pm 0.8$ \\
$\begin{array}{l}\text { Large decidual cells (LDC) zone } \\
\text { ratio in deciduas section after } \\
\text { eMSC transplantation, (\%) }\end{array}$ & $35.4 \pm 3.6$ & $31.8 \pm 1.6$ \\
$\begin{array}{l}\text { Large decidual cells (LDC) zone } \\
\text { ratio in deciduas section after } \\
\text { eBMC transplantation, (\%) }\end{array}$ & $38.3 \pm 7.3$ & $45.1 \pm 9.0$ \\
\hline
\end{tabular}

during the next three-six months. However, there are data on successful application of autologous bone marrow cells for Asherman's syndrome treatment [25]. The
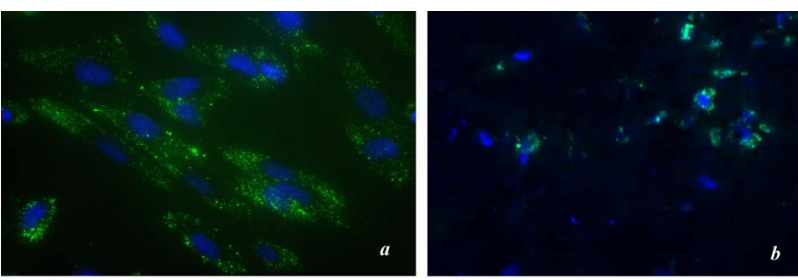

Figure 6. Blue fluorescence of nuclei and green fluorescence of membranes in cultured eMSC double stained with membrane dye PKH 67 Green and nuclear staining dye Hoechst 332: (a) eMSC in culture Ob. 40×; (b) experimental decidua tissue section Ob. $20 \times$.

authors described a clinical case of the Asherman's syndrome infertility when intrauterine injection of CD9, CD44 and CD90 positive autologous bone marrow cells to the patient led to increase in thickness of endometrium and successful pregnancy occurrence. In conclusion, we demonstrated for the first time that eMSC transplantation into pseudopregnant rat facilitates the development of all elements of decidual tissue. It opens the possibility that eMSCs may be applied for the cell therapy of infertility associated with decidualzation insufficiency. The MSCs harvested from bone marrow demand an invasive procedure that is painful and risky for patients. A noninvasive and easily available source for isolation of eMSCs, their plasticity, high proliferation activity during long-term cultivation, genetic stability, lack of tumorigenecity [26] and low immunogenicity, as well as positive results on cell therapy in experimental animals, makes the eMSCs from menstrual blood a promising source of stem cells for future clinical applications, including reproduction technology.

\section{ACKNOWLEDGEMENTS}

The work was supported by the program "Russian Leading Scientific School” No. 4957.2012.4 and MCB RAS Program.

\section{REFERENCES}

[1] Kim, J.J., Taylor, H.S., Lu, Z, Ladhani, O., Hastings, J.M., Jackson, K.S., Wu, Y, Guo, S.W. and Fazleabas, A.T. (2007) Altered expression of HOXA10 in endometriosis: Potential role in decidualization. Molecular Human Reproduction, 13, 323-332. doi:10.1093/molehr/gam005

[2] Gu, Y., Soares, M.J., Srivastava, R.K. and Gibori, G. (1994) Expression of decidual prolactin-related protein in the rat decidua. Endocrinology, 135, 1422-1427. doi:10.1210/en.135.4.1422

[3] Rahkonen, L., Rutanen, E.M., Nuutila, M., Sainio, S., Saisto, T. and Paavonen, J. (2010) Elevated levels of decidual insulin-like growth factor binding protein-1 in cervical fluid in early and mid-pregnancy are associated with an increased risk of spontaneous preterm delivery. BJOG, 117, 701-710. doi:10.1111/j.1471-0528.2010.02551.x 
[4] Kearns, M. and Lala, P.K. (1982) Bone marrow origin of decidual cell precursors in the pseudopregnant mouse uterus. The Journal of Experimental Medicine, 155, 15371554. doi:10.1084/jem.155.5.1537

[5] Bell, S.C. (1983) Decidualization: regional differentiation and associated function. Oxford Reviews of Reproductive Biology, 5, 220-271.

[6] Brosens, J.J. and Gellersen, B. (2006) Death or survival-Progesterone-dependent cell fate decisions in the human endometrial stroma. Journal of Molecular Endocrinology, 36, 389-398. doi:10.1677/jme.1.02060

[7] Finn, C.A., Pope, M.D. and Milligan, S.R. (1996) Relaxin and decidualization in mice: A reappraisal. Biology of Reproduction, 55, 1415-1418. doi:10.1095/biolreprod55.6.1415

[8] Finn, C.A. and Keen, P.M. (1963) The induction of deciduomata in the rat. Journal of Embryology \& Experimental Morphology, 11, 673-682.

[9] Toshihiro, K., Amanda, R.G., Lea, A.R., Jennifer, K., HoChen, S.M., Khorshed, A., Pengli, B.M.A., Karim, R. and Michael, J.S. (2010) Subfertility linked to combined luteal insufficiency and uterine progesterone resistance. Endocrinology, 151, 4537-4550. doi:10.1210/en.2010-0440

[10] Krehbiel, R.H. (1937) Cytological studies of the decidual reaction in the rat during early pregnancy and in the production of deciduomata. Physiological Zoology, 10, 212234.

[11] Mikhailov, V.M. (2003) Life cycle of decidual cells. International Review of Cytology, 227, 1-63. doi:10.1016/S0074-7696(03)01007-6

[12] Taylor, H.S. (2004) Endometrial cells derived from donor stem cells in bone marrow transplant recipients. The Journal of the American Medical Association, 292, 81-85. doi:10.1001/jama.292.1.81

[13] Schwab, K.E. and Gargett, C.E. (2007) Co expression of two perivascular cell markers isolates mesenchymal stem like cells from human endometrium. Human Reproduction, 22, 2903-2911. doi:10.1093/humrep/dem265

[14] Cho, N.H., Park, Y.K., Kim, Y.T., Yang, H. and Kim, S.K. (2004) Lifetime expression of stem cell markers in the uterine endometrium. Fertility and Sterility, 81, 403-407. doi:10.1016/j.fertnstert.2003.07.015

[15] Gargett, C.E. (2006) Identification and characterization of human endometrial stem/progenitor cells. Australian and New Zealand Journal of Obstetrics and Gynaecology, 46, 250-253. doi:10.1111/j.1479-828X.2006.00582.x

[16] Meng, X., Ichim, T.E., Zhong, J., Rogers, A., Yin, Z., Jackson, J., Wang, H., Ge, W., Bogin, V., Chan, K.W., Thébaud, B. and Riordan, N.H. (2007) Endometrial regenerative cells: A novel stem cell population. Journal of Translational Medicine, 5, 57-66. doi:10.1186/1479-5876-5-57

[17] Musina, R.A., Belyavsky, A.V., Tarusova, O.V., Solovyeva, E.V. and Sukhikh G.T. (2008) Endometrial mesenchymal stem cells obtained from menstrual blood, klet. tekhn. Biology and Medicine, 2, 110-114.

[18] Patel, A.N., Park, E., Kuzman, M., Benetti, F., Silva, F.J. and Allickson, J.G. (2008) Multipotent menstrual blood stromal stem cells: Isolation, characterization, and differentiation. Cell Transplant, 17, 303-311. doi:10.3727/096368908784153922

[19] Zemelko, V.I., Grinchuk, T.M., Domnina, A.P., Artzibasheva, I.V., Zenin, V.V., Kirsanov, A.A., Bichevaia, N.K., Korsak, V.S. and Nikolsky, N.N. (2012) Multipotent mesenchymal stem cells of desquamated endometrium: Isolation, characterization, and application as a feeder layer for maintenance of human embryonic stem cells. Cell and Tissue Biology, 6, 1-11. doi:10.1134/S1990519X12010129

[20] Gargett, C.E. and Masuda, H. (2010) Adult stem cells in the endometrium. Molecular Human Reproduction, 16, 818-834. doi:10.1093/molehr/gaq061

[21] Zemelko, V.I., Kozhukharova, I.B., Alekseenko, L.L., Domnina, A.P., Reshetnikova, G.F., Puzanov, M.V., Dmitrieva, R.I., Grinchuk, T.M., Nikolsky, N.N. and Anisimov, S.V. (2013) Neurogenic potential of human mesenchymal stem cells isolated from bone marrow, adipose tissue and endometrium: A comparative study. Cell and Tissue Biology, 7, 235-244. doi:10.1134/S1990519X13030140

[22] Beer, A.E. and Billingham, R.E. (1974) Host responses to intrauterine tissue, cellular and fetal allografts. Journal of Reproduction \& Fertility, 21, 59.

[23] Csemiczky, G., Wramsby, H., Johannisson, E. and Landgren, B.M. (1998) Importance of endometrial quality in women with tubal infertility during a natural menstrual cycle for the outcome of IVF treatment. Journal of Assisted Reproduction and Genetics, 15, 55-61. doi:10.1007/BF02766825

[24] Dmowski, W.P. and Greenblatt, R.B. (1969) Asherman's syndrome and risk of placenta accreta. Obstetrics \& Gynecology, 34, 288-299.

[25] Nagori, C.B., Panchal, S.Y. and Patel, H. (2011) Endometrial regeneration using autologous adult stem cells followed by conception by in vitro fertilization in a patient of severe Asherman's syndrome. Journal of Human Reproductive Sciences, 4, 43-48. doi:10.4103/0974-1208.82360

[26] Domnina, A.P., Fridlyanskaya, I.I., Zemelko, V.I., Pugovkina, N.A., Kovaleva, Z.V., Zenin, V.V., Grinchuk, T.M. and Nikolsky, N.N. (2013) Mesenchymal stem cells from human endometrium do not undergo spontaneous transformation during long-term cultivation. Cell and Tissue Biology, 7, 221-226. doi:10.1134/S1990519X1303005X 